\title{
Magnitude of Nosocomial Infection in Neonatal Intensive Care Unit at Benha Children Hospital
}

O.A.Elfiki ${ }^{1}$, A.A.Dawah ${ }^{2}$, E.H. Asser ${ }^{3}$, A.A.Abdel Rahman ${ }^{4}$

${ }^{1}$ Professor and head of Pediatrics dept., Faculty of medicine, Benha Univ., Egypt

${ }^{2}$ Former Professor of Public Health, Faculty of medicine, Benha Univ., Egypt

${ }^{3}$ Assistant professor of Pediatrics, Faculty of medicine, Benha Univ., Egypt

${ }^{4}$ M.B.B.Ch, Faculty of Medicine, BenhaUniv., Benha. Egypt

E-Mail: ahmedabdelghafar25@gmail.com

\begin{abstract}
Background

A nosocomial infection is an infection in which the clinical, laboratorial and microbiological diagnostic evidence is found after the first 48 hours of admission in a hospital unit. The objectives of this study were to determine the incidence of nosocomial infection in NICU Benha children hospital and to study the risk factors of nosocomial infection.

Subjects and Methods: The present study is cross sectional was carried out at Neonatal Intensive Care Unit of Benha Hospital during the period from the start of Jan. 2018 to the end of June 2018

.Data were collected through the following tools: a) Sociographic Data include: Gender, Date of birth, Gestational age in weeks

b) Medical Data include (1) Interventions done to the neonates at the unit: invasive procedure, device exposure and treatments received. (2) Presence of risk factors for infection: weight in grams, Mode of delivery, Presence of congenital anomalies, length of stay.3) Laboratory investigations as count blood cells and blood culture.

Results: The percentage of HAI was $(23 \%)$. BSI $(68.42 \%)$ and VAP $(31.58 \%)$ There was no statistically significant difference between HAI and Non HAI regarding age on admission, Sex and Mode of delivery. There was statistically significant decrease in G. Age and weight among HAI than Non HAI. There was statistically significant difference between HAI and Non HAI regarding Fate. There was statistically significant increase in Period of stay among HAI than Non HAI.

Conclusion: Nosocomial infection in the studied NICU was a relatively high and causes high mortality rates. Low birth weight as well as gestational age and length of stay in hospital were important risk factors in such, infections. However, multi-center studies are needed to confirm these findings.
\end{abstract}

Keywords: Nosocomial infection, Neonatal Intensive Care Unit, risk factors.

\section{Introduction}

A nosocomial infection is an infection in which the clinical, laboratorial and microbiological diagnostic evidence is found after the first 48 hours of admission in a hospital unit. Nosocomial infection is a common complication in hospitalized patients and is an important cause of morbidity and mortality in neonatal intensive care units (NICUs).Neonatal mortality, or death in the first 28 days of life, accounts for one-third of child mortality worldwide [1].

Nosocomial infections, particularly in NICUs, are recognized as one of the most important causes of morbidity and mortality in hospitalized neonates. [2].The incidence of nosocomial infection varies between $18 \%$ and $34 \%$ and accounts for as much as $40 \%$ of all neonatal deaths in developing countries [3].

Studies suggest that approximately one-third of nosocomial infections would be preventable if hospitals had effective infection control protocols. Despite epidemiological surveillance programs and preventative measures to control nosocomial infections, the risk of their development remains unacceptably high [4].

Infections that are acquired in neonatal units are unique in many aspects. Newborns are extremely susceptible to infections for several reasons: their immune systems are still developing, so they have inefficient mucosal and cutaneous barriers, and they are exposed to variety of therapeutic interventions, such as the use of invasive devices and broadspectrum antimicrobials. These therapeutic interventions make newborns targets for infectious agents and the complications that follow. The defenses are even more fragile in premature neonates and in newborns with a low birth weight [3]

The objectives of this study were to determine the incidence of nosocomial infection in NICU Benha children hospital and to study the risk factors of nosocomial infection.

\section{Subjects and methods}

The present study is cross sectional was carried out at Neonatal Intensive Care Unit of Benha Hospital during the period from the start of January 2018 to the end of June 2018.

\section{Research design}

\section{I- Administrive design}

An approval from the Research Ethic Committee in Benha faculty of medicine .Official permission were taken from hospitals administrators to facilitate the work, a clear explanation was given about the nature, importance and expected outcomes of the study. 


\section{II- Technical design}

Descriptive design was utilized to conduct this study.

1-Technical Design includes the setting, subject, and tools of data collection.

Subjects

The subject were consisted of:

All neonates admitted to NICU and stayed 48 hours in this unit within six months for data collection.

\section{Criteria of neonates}

-All neonates for mothers with Gestational age between 28-40 weeks.

- Sex: Both sexes.

-All diagnosed cases.

-Stayed more than 48 hours in unit.

\section{Tools of Data Collection}

Data were collected through the following tools:

a) Sociographic data include: Gender, date of birth, gestational age in weeks

b) Medical data include

1) Interventions done to the neonates at the unit: invasive procedure, device exposure and treatments received.

2) Nosocomial risk factors which include:

Total parenteral nutrition, central venous catheterization, peripheral venous catheterization, urinary catheterization, artificial respiration, oxygen box or nasal prongs utilization, empirical antibiotics administration and corticosteroids administration, blood or plasma transfusion, infection date and mortality date.

3) Presence of risk factors for infection: weight in grams, mode of delivery, presence of congenital anomalies and length of stay.

4) Laboratory investigations as count blood cells, blood culture and $\mathrm{C}$ reactive protein.

\section{III - Operational Design}

\section{a) Preparatory phase}

A review will have done of the available local and international, pervious and current related literature to get acquainted with the nature of the study and to cover various aspects of nosocomial infection in neonatal intensive care unit Benha children hospital and to design the study tools.

\section{b) Filed work}

The actual field work will carried out the start of January 2018 to the end of June 2018 for data collection. The researcher explained the aim of the study for studying nurses to gain their cooperation, and then written agreement to participate in the study was taken.

\section{c) Ethical considerations}

A written consent will obtained from all hospital staff members to participate in the study after a brief explanation for the aim of the study.

\section{d) Pilot study}

A pilot study will conducted on $10 \%$ of the study subjects to evaluate the effectiveness of the applicability of the study tools and estimate the time consumed to apply the tool. According to the results obtained from the pilot study, the necessary modifications were done.

\section{Statistical analysis}

The collected data were tabulated and analyzed using SPSS version 16 software (Spss Inc, Chicago, ILL Company). Categorical data were presented as number and percentages. Chi square test $\left(\mathrm{X}^{2}\right)$, or Fisher's exact test (FET) were used to analyze categorical variables. Quantitative data were tested for normality using Kolomogrov Smirnove test assuming normality at $\mathrm{P}>0.05$. Quantitative data were expressed as mean \pm standard deviation, median and range. Student " $t$ " test was used to analyze normally distributed variables among 2 independent groups, or Man Whitney $\mathrm{U}$ test for nonparametric ones. The accepted level of significance in this work was stated at $0.05 \quad(\mathrm{P}<0.05$ was considered significant).

\section{Results}

Results in table (1) showed that the Mean of the Gestational age (wks. $)=(35.2 \pm 3.1)$, age on admission $=(6.7 \pm 6.5)$, weight $=(2443 \pm 869)$, the percentage of the Female $=(43.6 \%)$, Male $=(56.4$ $\%)$, Caesarean section $=(80 \%), \operatorname{NVD}=(20 \%)$. Results in table (2) showed that the percentage of the Alive was $(84.8 \%)$, Died $(15.2 \%)$. Results in table (3) showed that the percentage of HAI was ( $23 \%)$. BSI $(68.4 \%)$ and VAP (31.5\%). Results in table (4) showed that the highest value was klebsiela $(42.1 \%)$, while (Candida and E coli) was the less value (5.2\%). Results in table (5) showed that there was no statistically significant difference between HAI and Non HAI regarding age on admission, Sex and Mode of delivery. There was statistically significant decrease in Gestational age and weight among HAI than Non HAI. Results in table (6) showed that there was statistically significant difference between HAI and Non HAI regarding Outcome. Results in table (7) showed that there was statistically significant increase in Period of stay among HAI than Non HAI. Results in table (8) showed that there was no statistically significant difference between HAI and Non HAI regarding PVC.There was statistically significant increase in PROM, Foley catheter Umbilical catheter, and CVC among HAI than Non HAI. Results in table (9) showed that there was statistically significant increase in MV duration and CPAP duration among HAI than Non HAI There was no statistically significant difference between HAI and Non HAI regarding CPAP.There was statistically significant difference between HAI and Non HAI regarding MV.

Table (1) Demographic data of the studied cases.

\begin{tabular}{lll}
\hline Demographic data & Range & Mean \pm SD \\
\hline 1- Gestational age (wks.) & $27-40$ & $35.22 \pm 3.118$ \\
2- age on admission & $1-28$ & $6.79 \pm 6.59$ \\
3- Weight(gm) & $750-4200$ & $2443.06 \pm 869.726$ \\
\hline
\end{tabular}




\begin{tabular}{lll}
\hline 4- Sex & No. & $\%$ \\
a- Female & 72 & 43.6 \\
b- Male & 93 & 56.4 \\
5- Mode of delivery & 132 & 80.0 \\
$\quad$ a- Caesarean section & & \\
$\quad$ b- Vaginal delivery & 33 & 20.0 \\
\hline
\end{tabular}

Table (2) Outcome of the studied cases.

\begin{tabular}{lcc}
\hline Outcome & No. & \% \\
\hline Alive & 140 & 84.8 \\
Dead & 25 & 15.2 \\
Total & 165 & 100.0 \\
\hline
\end{tabular}

Table (3) HAI among the studied cases

\begin{tabular}{lllll}
\hline \multirow{2}{*}{ Variable } & Yes & & No & \\
\cline { 2 - 5 } & No & \% & no & \% \\
\hline HAI & 38 & 23.0 & 127 & 77.0 \\
BSI & 26 & 15.7 & 144 & 84.3 \\
VAP & 12 & 7.2 & 153 & 92.8 \\
\hline
\end{tabular}

$\mathrm{HAI}=$ Hospital acquired infection $\quad \mathrm{BSI}=\mathrm{Blood}$ stream infection VAP=Ventilator-associated pneumonia

Table (4) Blood culture among HAI

\begin{tabular}{lll}
\hline & No. & \% \\
\hline Candida & 2 & 5.2 \\
klebsiela & 16 & 42.1 \\
MRSA & 3 & 7.8 \\
E coli & 2 & 5.2 \\
pseudomonas & 4 & 10.5 \\
staphylococcus aureus & 11 & 28.9 \\
\hline
\end{tabular}

Table (5) Comparison between HAI and Non HAI regarding Demographic data

\begin{tabular}{|c|c|c|c|c|c|c|}
\hline HAI & \multicolumn{2}{|c|}{$\begin{array}{c}\text { No } \\
\text { Mean } \pm \text { SD }\end{array}$} & \multicolumn{2}{|c|}{$\begin{array}{c}\text { Yes } \\
\text { Mean } \pm \text { SD }\end{array}$} & $\begin{array}{c}\text { Test of } \\
\text { significance }\end{array}$ & $\begin{array}{c}P . \\
\text { value }\end{array}$ \\
\hline 1-Gestational age & \multicolumn{2}{|c|}{$35.78 \pm 2.746$} & \multicolumn{2}{|c|}{$33.37 \pm 3.58$} & $\mathrm{t}=4.411$ & 0.000 \\
\hline 2- age on admission & \multicolumn{2}{|c|}{$7.06 \pm 7.03$} & \multicolumn{2}{|c|}{$5.89 \pm 4.8$} & $\mathrm{t}=0.958$ & 0.340 \\
\hline \multirow[t]{2}{*}{ 3- weight } & \multicolumn{2}{|c|}{$2543 \pm 842$} & \multicolumn{2}{|c|}{$2035 \pm 919$} & $\mathrm{t}=3.197$ & 0.002 \\
\hline & No & $\%$ & No & $\%$ & & \\
\hline \multicolumn{7}{|l|}{ 4- Sex } \\
\hline a-- female & 55 & 43.3 & 17 & 44.7 & $\begin{array}{c}x \\
0.024\end{array}$ & .876 \\
\hline b- male & 72 & 56.7 & 21 & 55.3 & & \\
\hline 5- Mode of delivery & \multicolumn{2}{|c|}{$\begin{array}{l}103 \\
81.1\end{array}$} & 29 & 76.3 & \multirow{2}{*}{$\begin{array}{c}X^{2} \\
0.419\end{array}$} & \multirow{2}{*}{0.518} \\
\hline b-Vaginal delivery & 24 & 18.9 & 9 & 23.7 & & \\
\hline
\end{tabular}

Table (6) Comparison between HAI and Non HAI regarding Outcome

\begin{tabular}{lllllll}
\hline & & & Non HAI & HAI & $\mathbf{X}^{\mathbf{2}}$ & P. value \\
\hline \multirow{3}{*}{ Outcome } & Alive & No. & 114 & 26 & & \\
& & $\boldsymbol{\%}$ & $89.8 \%$ & $68.4 \%$ & 10.363 & .001 \\
& Dead & No. & 13 & 12 & & \\
\hline
\end{tabular}

Table (7) Comparison between HAI and Non HAI regarding Period of stay

\begin{tabular}{llllll}
\hline & & Non HAI & HAI & t. test & P. value \\
\hline Period of stay & Mean \pm SD & $16.39 \pm 11.452$ & $47.24 \pm 40.242$ & $-7.705-$ & 0.000 \\
\hline
\end{tabular}


Table (8) Comparison between HAI and Non HAI regarding Examination.

\begin{tabular}{|c|c|c|c|c|c|c|}
\hline & & & Non HAI & HAI & $\mathbf{X}^{2}$ & P. value \\
\hline \multirow{4}{*}{ PROM } & & No. & 94 & 16 & \multirow{4}{*}{13.402} & \multirow{4}{*}{$.00 \cdot$} \\
\hline & No & $\%$ & $74.0 \%$ & $42.1 \%$ & & \\
\hline & & No. & 33 & 22 & & \\
\hline & Yes & $\%$ & $26.0 \%$ & $57.9 \%$ & & \\
\hline \multirow{4}{*}{$\begin{array}{l}\text { Umbilical } \\
\text { catheter }\end{array}$} & No & No. & 122 & 33 & \multirow{4}{*}{4.368} & \multirow{4}{*}{.037} \\
\hline & No & $\%$ & $96.1 \%$ & $86.8 \%$ & & \\
\hline & Yes & No. & 5 & 5 & & \\
\hline & Yes & $\%$ & $3.9 \%$ & $13.2 \%$ & & \\
\hline \multirow{4}{*}{ Foley catheter } & No & No. & 125 & 34 & \multirow{4}{*}{6.68} & \multirow{4}{*}{.010} \\
\hline & & $\%$ & $98.4 \%$ & $89.5 \%$ & & \\
\hline & Yes & No. & 2 & 4 & & \\
\hline & Yes & $\%$ & $1.6 \%$ & $10.5 \%$ & & \\
\hline \multirow{4}{*}{ CVC } & No & No. & 103 & 11 & \multirow{4}{*}{37.25} & \multirow{4}{*}{.000} \\
\hline & No & $\%$ & $81.1 \%$ & $28.9 \%$ & & \\
\hline & Yes & No. & 24 & 27 & & \\
\hline & Yes & $\%$ & $18.9 \%$ & $71.1 \%$ & & \\
\hline \multirow{4}{*}{ PVC } & No & No. & 3 & 2 & \multirow{4}{*}{.838} & \multirow{4}{*}{.36} \\
\hline & No & $\%$ & $2.4 \%$ & $5.3 \%$ & & \\
\hline & & No. & 124 & 36 & & \\
\hline & Yes & $\%$ & $97.6 \%$ & $94.7 \%$ & & \\
\hline
\end{tabular}

PROM=Premature rupture of membranes

$\mathrm{CVC}=$ Central venous catheter

$\mathrm{PVC}=$ Peripheral venous catheter

Table (9) Comparison between HAI and Non HAI regarding MV and CPAP.

\begin{tabular}{|c|c|c|c|c|c|c|}
\hline & & & Non HAI & HAI & t. test & P. value \\
\hline MV duration & \multicolumn{2}{|c|}{ Mean \pm SD } & $11.02 \pm 10.296$ & $33.41 \pm 29.356$ & $-5.416-$ & 0.000 \\
\hline CPAP duration & \multicolumn{2}{|c|}{ Mean \pm SD } & $3.45 \pm 1.33$ & $5.64 \pm 1.76$ & $-5.908-$ & 0.000 \\
\hline MV & no & $\begin{array}{l}\text { No. } \\
\% \\
\text { No. } \\
\%\end{array}$ & $\begin{array}{c}62 \\
48.8 \% \\
65 \\
512 \%\end{array}$ & $\begin{array}{c}32 \\
84.2 \% \\
6 \\
15.8 \%\end{array}$ & $\begin{array}{c}X^{2} \\
14.945\end{array}$ & 0.00 . \\
\hline CPAP & no & $\begin{array}{l}\text { No. } \\
\% \\
\text { No. } \\
\%\end{array}$ & $\begin{array}{c}53 \\
41.7 \% \\
74 \\
58.3 \%\end{array}$ & $\begin{array}{c}21 \\
55.3 \% \\
17 \\
44.7 \%\end{array}$ & $\begin{array}{c}X^{2} \\
2.165\end{array}$ & 0.141 \\
\hline
\end{tabular}

$\mathrm{CPAP}=$ Continuous positive airway pressure

$\mathrm{Mv}=$ Mechanical Ventilator

\section{Discussion}

The present study is cross sectional was carried out at Neonatal Intensive Care Unit of Benha Hospital during the period from the start of Jan. 2018 to the end of June 2018. This study was conducted on 165 neonate with mean of the G. Age was $(35.22 \pm 3.118)$, age on admission $(6.79 \pm 6.594)$, weight $(2443.06 \pm$ $869.726)$, the percentage of the female $(43.6 \%)$ and male $(56.4 \%)$, CS $(80 \%)$, NVD $(20 \%)$.

In the present study, caesarian rates reached $80 \%$.According to the World Health Organization (WHO), caesarian delivery should correspond to a maximum of $15 \%$ of births. However, using data from the public and private sectors in Brazil, the Ministry of Health reports that caesarians correspond to $43 \%$ of births. For private health care plans, the caesarian rates are as high as $80 \%$. In the Unified Health
System of Brazil, caesarians account for $26 \%$ of all deliveries. [5].

A normal delivery is the safest option for the mother and baby. Because they are a surgical procedure, caesarians should only be indicated in situations that are high risk for the mother or fetus. However, caesarians are often scheduled before labor commences, which increases the risk of newborns developing acute respiratory problems. Consequently, caesarians can increase the need for NICU admission. [6].

National rates of $52.5 \%$ in [7]. And $40.8 \%$ in [8]. International rates of $48.8 \%$ in [9]. And $62.8 \%$ in [10]. Are also lower. These rates are all above the rate that is recommended by the WHO.

This study showed that, incidence of nosocomial infection in NICU Benha children hospital was $23 \%$. 
A similar result was reported in a recent study [11]. Carried out at NICU in Mansoura University, Mansoura, Egypt, in 2013, where the rate of nosocomial infection was $21.4 \%$.

In Egypt [12]. reported that the rate of occurrence of nosocomial neonatal infections in Benha University

NICU is estimated to be $54 \%$ among all neonates admitted to the unit.

[13]. reported an incidence of $50.7 \%$, and [14]. reported an incidence of $36.6 \%$. However, other recent Brazilian studies have reported lower incidence rates, such as $14.5 \%$ in [15]. and $18.3 \%$ in [16].

In international studies, the incidence of nosocomial infection varies between $10 \%$ and 30\%.[17]. The differences among the studies can be attributed to different surveillance methods for calculating the incidence of nosocomial infection. However, international rates are much lower than what was found in the present study and what has been reported in other national studies. The elevated rates may be partially attributed to overcrowded units, differences in work situations, inadequate facilities within units (i.e., less space between beds than is recommended by ANVISA and the CDC), insufficient equipment and understaffing. These problems are chronic and persistent in NICUs in developing countries.[13]. However, there have been wide variations in the reported incidence of NI rates according to the NICUs. In the United States, NI rates vary from 6 to greater than $40 \%$ [18]. and in one study, the incidence has been reported to be as high as 70\% [19].

In the present study, among HAI cases, Blood stream infection (BSI) was $(68.42 \%)$ and ventilator associated pneumonia (VAP) was (31.58\%).

Worldwide bloodstream infections are reported to be the most common NI with an incidence as high as $78 \%$ of the total NIs reported [20].This disagrees with the results of [11]. Who found pneumonia was the commonest detected infection (32.9\%); with most of them $(81.5 \%)$ were ventilator associated pneumonia (VAP). Blood stream infection was $26.8 \%$ of the detected infections in their studied neonates. The next most common site of infection varies among NICUs but is often in either the respiratory [18]. or urinary tract [20]. These sites of infection were also reported in our study but at relatively lower rates than those reported in previous studies.

In our study, there was statistically significant decrease in gestational age and weight among HAI than Non HAI.This agrees with [1]. who found that low gestational age and lower birth weight placed infants at a higher risk of developing HAI. As indicated in other studies, this finding could be due to the patients' immature immune system, long duration of hospitalization, and use of invasive procedures [21].Consistent with our study, [22]. found that HCAI was more frequent among low birth weight infants than high birth infants.

This study showed that, nosocomial infection a mortality rate of $31.6 \%$.In a cohort study performed in
Londrina, [13]. found a nosocomial infection mortality rate of $24.1 \%$, which is closer to the rate in the present study $(31.6 \%)$. It is extremely difficult to establish the role that nosocomial infection has on the death of a neonate who is admitted to a NICU. Infants are vulnerable to many complications from their initial condition, and several coexisting factors can contribute to undesirable outcomes.

This is higher than the rate that was reported by [23]. in an Italian cohort study (12.7\%). The mortality rates in NICUs in developed countries, which vary from $6.1 \%$ to $7.1 \%$.[17].

In recent years, an increase in the survival rate of neonates can be attributed to improvements in the quality of and access to health care services. [16]. Morbidity and mortality can be reduced with better infrastructure, more advanced technologies, improved access to knowledge and training in infection control processes, better health care systems and additional financial resources. [24].

This study showed that, there was statistically significant increase in Period of stay, PROM, Umbilical catheter, Foley catheter and CVP, MV, MV duration and CPAP duration among HAI than Non HAI. These findings coincides with the results of a previous study [25].who found, Length of hospitalization, mechanical ventilation, umbilical catheter, use of antibiotics, and intubation at birth were associated with a significantly increased risk of HCAI.

This agrees also with [26]. who found that endotracheal intubation at birth, mechanical ventilation and assisted ventilation by continuous positive pressure through nasal prongs, central venous catheter, parenteral nutrition, continuous enteral nutrition, premature rupture of membranes, cesarean section, male sex, aspiration, congenital anomalies, intracranial hemorrhage, and surgical intervention were associated with a significantly increased risk of HCAI.The most common isolates in this study was klebsiela $(36.8 \%)$, followed by staphylococci $(28.9 \%)$ and Pseudomonas (10.5\%).

In study conducted in NICU in Ankara, Turkey, however, Gram-negative bacteria were isolated from the infected neonates at a rate of $70.8 \%$, grampositive at $22.6 \%$ and Candida species at $6.6 \%$. The most commonly isolated microorganisms were, in order of frequency, Klebsiella (39.6\%), Pseudomonas aeruginosa $(11.3 \%)$ and Coagulase-negative staphylococci (9.4\%) [29]. In another study, the most commonly isolated microorganisms from the studied 154 neonatal nosocomial infections were Acinetobacter (47.9\%), Pseudomonas (23.6\%), and Klebsiella/Enterobacter (8.3\%). Coagulase- negative staphylococci (8.3\%) and Staphylococcus aureus $(6.3 \%)$ were the most frequently reported Grampositive bacteria [27] and [26]. reported that the most common causative agents isolated from NIs were Klebsiella-Enterobacter (39.3\%), Escherichia coli (25.0\%), coagulase-negative Staphylococci (16.1\%), 
Acinetobacter spp. (10.7\%), Candida albicans (5.4\%), and Stenotrophomonas maltophilia (3.6\%)

The variations observed in this and other studies regarding the frequency of the isolated microorganisms might be attributed to the different hospital environments where the studies were conducted, antibiotic resistance as well as the time where swabs were taken. For early onset sepsis, the Gram negative bacilli as a group were found to be the commonest organisms implicated in neonatal infection while Staphylococcus aureus was reported to be the commonest cause of late onset sepsis [28].

\section{Conclusion}

This study concluded that, Nosocomial infection in the studied NICU was a relatively high and causes high mortality rates. Low birth weight as well as gestational age and length of stay in hospital were important risk factors in such, infections. However, multi-center studies are needed to confirm these findings.

\section{References}

[1] K. Dal-Bó, R. Silva, Sakae, etal. Nosocomial infections in a neonatal intensive care unit in South Brazil. Infecção hospitalar em uma unidade de terapia intensiva neonatal do Sul do Brasil. Revista Brasileira de terapia intensive, ,vol. 24(4),pp. 381-385. 2012

[2] AA. Mohammed, AB .Ali and NH. Refaat. A descriptive study on the diagnosis and treatment of ventilator-associated pneumonia in the neonatal intensive care unit of Assiut University Children's Hospital. J Curr Med Res Pract, vol.4, pp.56-60, 2019.

[3] J. Cabral, and AG, R. Blue Light Disinfection in Hospital Infection Control: Advantages, Drawbacks, and Pitfalls. Antibiotics, vol. 8(2), pp. 58. 2019.

[4] M. Haque, M. Sartelli, J. McKimm, et al. Health care-associated infections - an overview. Infection and drug resistance, vol 11, pp. 2321-2333. doi:10.2147/IDR.S177247,2018.

[5] Brazil. Ministério da Saúde. Portal da Saúde [Acesso em 6 de junho de];Campanha Incentivo ao Parto Normal. Disponível em:http://portal.saude.gov.br/portal/saude/visualiz ar_texto.cfm?idtxt=28513, 2011.

[6] S. Farchi, D. Di Lallo, F. Franco, A .Polo, Lucchini R, Calzolari, et al. Neonatal respiratory morbidity and mode of delivery in a population-based study of low-risk pregnancies. Acta Obstet Gynecol Scand, vol. 88(6), pp.729-732, 2009.

[7] AC. Távora, AB. Castro, MA. Militão, JE. Girão, KB. Ribeiro, LG. Távora. Risk factors for nosocomial infection in a Brazilian neonatal intensive care unit. Braz J Infect Dis, vol.12 (1), pp.75-79, 2008.

[8] MS. Pinheiro, C. Nicoletti, I. Boszczowk, DM. Puccini, SR. Ramos. Infecção hospitalar em unidade de terapia intensiva neonatal: há influência do local de nascimento? Rev Paul Pediatr, vol.27 (1), pp.6-14, 2009.

[9] WC. Van der Zwet, AM.Kaiser, RM. van Elburg, J. Berkhof, WP. Fetter, GA. Parlevliet, et al. Nosocomial infection in a Dutch neonatal intensive care unit: surveillance study with definitions for infection specifically adapted for neonates. J Hosp Infect.; vol.61 (4), pp300-311, 2005.

[10] I Jeong, J Jeong and Choi EO, Epidemiological characteristics of nosocomial infection in a Newborn Intensive Care Unit (NICU), South Korea. BMC Infect Dis, vol.6, pp.103, 2006.

[11] F.Abdel-Wahab, M. Ghoneim, M. Khashaba, A.H. El-Gilany and D. Abdel-Hady. Nosocomial infection surveillance in an Egyptian neonatal intensive care unit. J. Hosp Infect, vol. 83(3), pp. 196-9, 2013.

[12]O El-Fiky, M El-Mahdy., A Shebl., Y AbdelMaksoud. and S.AbdelRhahman.Epidemiological study of nosocomial infection of neonates admitted to Benha university neonatal intensive care unit. Benha $\mathrm{M}$ J, vol. 20, pp.539-556, 2003.

[13] E. Nagata, AS .Brito and Matsuo T. Nosocomial infections in a neonatal intensive care unit: incidence and risk factors. Am J Infect Control, vol. (30|), pp. 26-31, 2002.

[14] RC. Couto, EA. Carvalho, TM. Pedrosa, ER. Pedroso, MC. Neto, FM.Biscione A 10-year prospective surveillance of nosocomial infections in neonatal intensive care units. Am J Infect Control, vol.35 (3), pp.183-189, 2007

[15] DV. Brito, CS.Brito, DS. Resende, Moreira do Ó J, VO .Abdallah, PP. Gontijo-Filho. Nosocomial infections in a Brazilian intensive care unit: a 4year surveillance study. Rev Soc Bras Med Trop, vol. 43(6), pp.633-637, 2010.

[16] GK. Lopes, EG. Rossetto, RA. Belei, Capobiango JD, Matsuo T. Estudo epidemiológico das infecções neonatais no Hospital universitário de Londrina, Estado do Paraná Acta Sci Health Sci, vol.; 30(1), pp.55-63, 2008.

[17] GB. Orsi, G. d'Etorre, A. Panero, F. Chiarini, V. Vullo, M. Venditti. Hospital-acquired infection surveillance in a neonatal intensive care unit. Am J Infect Control, vol.37 (3), pp.201-203, 2009.

[18] RL. Schelonka, S. Scruggs, K. Nichols, Dimmitt, RA and Carlo WA. Sustained reductions in neonatal nosocomial infection rates following a comprehensive infection control intervention. J Perinatol, vol. 26 (3), pp. 176-9, 2006.

[19] J.H. Hwang, C.W. Choi and Y.S. Chang, The efficacy of clinical strategies to reduce nosocomial sepsis in extremely low birth weight infants. J. Korean Med Sci., vol. 20, pp. 177-181, 2005.

[20] M.M. Efird, M.A. Rojas and J.M. Lozano, Epidemiology of nosocomial infections in selected neonatal intensive care units in Columbia, South America. J. Perinatol, vol. 25, pp. 531-536, 2005. 
[21] SE. Perlman, L. Saiman, EL. Larson. Risk factors for late-onset health care-associated bloodstream infections in patients in neonatal intensive care units. Am J Infect Control, vol.35 (3), pp.177182, 2007.

[22] RM Kishk, MF Mandour, RM Farghaly, A Ibrahim, Nemr NA. Pattern of Blood Stream Infections within Neonatal Intensive Care Unit, Suez Canal University Hospital, Ismailia, Egypt. Int J Microbiol, vol.276873. Doi, pp. 10, 2014.

[23] C. Auriti, A. Maccallini, G. Di Liso, V. Di Ciommo, MP. Ronchetti, M. Orzalesi. Risk factors for nosocomial infections in a neonatal intensive-care unit. J Hosp Infect, vol.53 (1), pp.25-30, 2003.

[24] AK. Zaid, WC. Huskins, D. Thaver, ZA. Bhutta, Z. Abbas, DA. Goldmann. Hospital- acquired neonatal infections in developing countries. Lancet, vol.365 (9465), pp.1175-1188, 2005.

[25] F. Aktar, R. Tekin, A. Gunes, C. Ulgen, Tan I, S. Ertugrul, et al. Determining the Independent Risk
Factors and Mortality Rate of Nosocomial Infections in Pediatric Patients. Biomed Res Int, vol.7240864, pp.1155, 2016.

[26] ZM.Djordjevic,Markovic-DenicL,Z.FolicMM, grutinovic, SM. Jankovic. Health care-acquired infections in neonatal intensive care units: risk factors and etiology. Am J InfectControl, vol.43 (1), pp.86-8.doi: 0.1016/j.ajic.10.005, 2014

[27] L. Markoviæ-Deniæ, J. Durisiæ, T. Nikoliæ, R. Ramadani, S. Iliæ and S. Stevanoviæ, Causative agents of neonatal nosocomial infections and their resistance to antibiotics. Med Preg, vol. 59(3-4), pp. 155-9, 2006.

[28] A.O. Mokuolu, N. Jiya and O.O. Adesiyun. Neonatal septicaemia in Ilorin: bacterial pathogens and antibiotic sensitivity pattern. Afr J Med. Med. Sic., vol. 31(2), pp. 127-30, 2002.

[29] Ba, A.Y., N. Demirel, A. Zenciroglu, N. Göl and G. Tanir,. Nosocomial blood stream infections in a neonatal intensive care unit in Ankara, Turkey Turk J. Pediatr., vol. 52(5), pp. 464-70, 2010. 